\title{
Cultivares de trigo submetidas a déficit hídrico no início do florescimento, em casa de vegetação ${ }^{1}$
}

\author{
Diego dos Santos ${ }^{2}$, Vandeir F. Guimarães ${ }^{3}$, Jeferson Klein ${ }^{4}$, \\ Samuel L. Fioreze ${ }^{5}$ \& Eurides K. Macedo Júnior ${ }^{6}$
}

\begin{abstract}
RESUMO
A restrição hídrica pode prejudicar o desempenho das culturas, em especial quando ocorre no período de florescimento. Desta forma, objetivou-se com esta pesquisa avaliar a resposta de genótipos de trigo submetidos a déficit hídrico no início do florescimento. O experimento foi conduzido em casa de vegetação, em delineamento inteiramente casualizado, em esquema fatorial $3 \times 2$, com cinco repetições, cujos fatores foram: três cultivares de trigo (Coodetec (CD) 105, 108 e 111) e dois manejos de irrigação (com e sem déficit hídrico). Durante o período de imposição do déficit hídrico, avaliaram-se a umidade gravimétrica do solo e o teor relativo de água das folhas enquanto no momento da reidratação foram avaliadas variáveis biométricas. Os componentes de produção foram avaliados ao final do ciclo. Constatou-se redução na umidade gravimétrica do solo, no teor relativo de água e em todas as variáveis biométricas, em função do déficit hídrico. A produção de grãos mostrou-se diferente apenas entre os regimes hídricos, em que a cultivar CD 111 é mais eficiente na manutenção do potencial produtivo em condições de déficit hídrico, mediante a rápida recuperação no teor relativo de água das folhas.
\end{abstract}

Palavras-chave: Triticum aestivum L., manejo de irrigação, parâmetros biométricos, teor relativo de água

\section{Wheat cultivars submitted to water deficit at the beginning of flowering in greenhouse}

\begin{abstract}
The water restriction can damage the performance of crops, especially in the flowering period. Thus, the aim of this research was to evaluate the response of genotypes of wheat submitted to water deficit in the beginning of flowering. The experiment was conducted in greenhouse, in a completely randomized design, in factorial scheme $3 \times 2$, with five replications. The factors studied were: three wheat cultivars (Coodetec (CD) 105, 108 and 111) and 2 irrigation managements (with and without imposition of water deficit). During the period of water deficit imposition, gravimetric soil moisture and the relative content of water in leaf were evaluated, while at the moment of rehydration the biometric variables were determined. At the end of the crop cycle the components of production were evaluated. Reduction was found in the gravimetric soil moisture, in the relative levels of water and in all biometric variables, in function of the water deficit. The grain production showed difference only among the water regimes, in which the cultivar CD 111 is more efficient in the maintenance of the productive potential in conditions of water deficit, through the quick recovery in the relative content of water in leaves.
\end{abstract}

Key words: Triticum aestivum L., irrigation management, biometric parameters, water relative content

\footnotetext{
Extraído do Trabalho de Conclusão de Curso do primeiro autor, apresentado à Universidade Estadual do Oeste do Paraná (UNIOESTE) UFFS, Avenida Oscar da Silva Guedes 01, Vila Albert, CEP 85303-820, Laranjeira do Sul, PR. Fone: (42) 3635-8650. E-mail: diegosagro@hotmail.com PPGA/UNIOESTE. Fone: (45) 3284-7911. E-mail: vandeirfg@yahoo.com.br

Bolsista PNPD/CAPES/UNIOESTE. Fone: (45) 3284-7911. E-mail: jefersonklein@yahoo.com.br

${ }^{5}$ FCA/UNESP. Fone: (45) 3284-7911. E-mail: sl_fioreze@hotmail.com

PPGA/UNIOESTE. Fone: (45) 3284-7911. E-mail: kuster@unioeste.br
} 


\section{INTRODUÇÃO}

O trigo (Triticum aestivum L.) é uma planta cultivada durante o inverno, com ciclo anual. No Brasil, o cultivo do trigo se restringiu, durante muitos anos, apenas à região Sul, devido principalmente a fatores culturais e bioclimáticos (Gutkoski et al., 2007). Contudo, o desenvolvimento de novas variedades e técnicas de manejo da cultura e da irrigação, associados à expansão da fronteira agrícola, resultaram em sua expansão para outras regiões, como a dos cerrados do Brasil Central (Boschini et al., 2011). No Paraná o avanço de novas tecnologias para as cultivares de trigo possibilitou obter cultivares adaptadas com produtividades significativamente superiores às obtidas nas demais regiões do Sul (Tavares et al., 2011).

Mesmo tendo cultivares mais tolerantes ao déficit hídrico, o controle da água disponível para o trigo é de fundamental importância durante a safra. Segundo Brunetta et al. (2006), o trigo requer, além de elevados índices pluviométricos, uma boa distribuição durante o ciclo para alcançar produtividade em torno de $3,5 \mathrm{t} \mathrm{ha}^{-1}$.

A perda de água do tecido da planta produz efeitos diretos, como redução do potencial químico ou atividade da água, além de aumentar a concentração de macromoléculas e de solutos de baixos pesos moleculares. Pode, também, interferir nas relações espaciais em membranas e organelas, através da redução do seu volume, reduzindo a pressão hidrostática dentro das células, além de outros (Carvalho et al., 2011). Desta forma, ressalta-se que a água é um recurso cada vez mais limitante ao desenvolvimento e produção vegetal e daí a necessidade de técnicas que permitam aumentar a produtividade das culturas a cada unidade de volume de água aplicada.

Alguns vegetais apresentam sensibilidade maior ao estresse hídrico, sendo metabolizados diversos reguladores vegetais imediatamente, assim que detectada a restrição hídrica (Taiz \& Zeiger, 2010). Este processo é rápido, visto que desencadeia uma cascata de alterações metabólicas que vão da raiz às folhas (Finkelstein et al., 2011).

Diversas respostas metabólicas protegem a planta contra a dessecação imediata. Sob tais condições, o rápido fechamento do estômato reduz a transpiração. Sendo assim, o seu fechamento é considerado mais uma linha de defesa contra a seca (Machado \& Sassaki, 1999; Taiz \& Zeiger, 2010).

Conforme Lawlor \& Uprety (1993), a principal causa da perda de produção sob estresse hídrico é a redução na área foliar, em virtude da redução do número e tamanho de folhas, produzindo menores taxas fotossintéticas por unidade de área. Esta condição de restrição hídrica também afeta negativamente o rendimento, sobremaneira interferir no número de grãos por área (Sousa \& Lima, 2010). Outra resposta indesejada à deficiência hídrica é a redução no número de grãos por espiga e não na massa seca de grãos, caracterizando desta forma, a fase de pré-antese como a mais sensível a deficiência hídrica (Rodrigues et al., 1998).

Estresses abióticos, como a seca, podem reduzir significativamente os rendimentos das lavouras e restringir os locais e os solos em que espécies comercialmente importantes poderiam ser cultivadas. Neste contexto, o presente trabalho teve por objetivo verificar o efeito do déficit hídrico imposto no início do florescimento sobre o teor relativo de água nas folhas, umidade gravimétrica do solo, parâmetros biométricos e produtividade de três cultivares de trigo.

\section{Material e MÉTOdos}

O experimento foi conduzido de junho a outubro de 2006, em ambiente protegido, na Estação de Horticultura e Cultivo Protegido Professor Mário Cesar Lopes, pertencente ao Núcleo de Estações Experimentais da Universidade Estadual do Oeste do Paraná - Unioeste, Campus de Marechal Cândido Rondon, PR. A estação está localizada nas coordenadas $54^{\circ} 22^{\prime} \mathrm{W}$ longitude, latitude $24^{\circ} 46^{\prime} \mathrm{S}$ e altitude de $420 \mathrm{~m}$. Três cultivares de trigo (CD 105, CD 108, CD 111) foram utilizadas com tolerância ao acamamento, crescimento determinado e ciclo total de 121, 115 e 125 dias, respectivamente (COODETE, 2012).

$\mathrm{O}$ experimento foi implantado em delineamento inteiramente casualizado, em esquema fatorial 3 x 2, com cinco repetições. Os tratamentos foram compostos de três cultivares cultivadas em dois regimes hídricos (um irrigado durante o ciclo e o outro com déficit hídrico no início do florescimento pelo período de dez dias). A parcela experimental foi constituída de um vaso contendo quatro plantas, totalizando 30 vasos.

Utilizaram-se vasos de polietileno, cilíndricos, $\operatorname{com} 20 \mathrm{~cm}$ de altura e $10 \mathrm{~cm}$ de raio, com volume para $6 \mathrm{~L}$ e utilizados, como substratos, $6 \mathrm{~kg}$ de uma mistura de terra argilosa proveniente de horizonte A de um Latossolo Vermelho Eutroférrico e areia, caracterizado granulometricamente em: 601,1; 36,3 e 362,6 g kg-1 respectivamente de areia, silte e argila. Inicialmente, todos os tratamentos foram mantidos irrigados com aplicação de água, de modo a manter a umidade do solo próximo à capacidade de campo, desde a semeadura. Para uma drenagem perfeita do excesso de água, os vasos continham orifícios na parte inferior objetivando mantê-los sempre próximo à capacidade de campo, até o início do florescimento.

O experimento teve, no total, 90 vasos, dos quais 30 vasos para as coletas de material durante a imposição do déficit hídrico, 30 para a análise biométrica no final do período de déficit e o restante para avaliação dos componentes de produção, no final do ciclo da cultura. Para o tratamento não irrigado (NI), a imposição do déficit hídrico foi realizada através da suspensão da irrigação das plantas no início da antese ocorrido aos 55 dias após a semeadura (DAS), permanecendo nesta condição até o teor relativo de água das folhas (TRA) atingir aproximadamente $45 \%$, isto é, aos 10 dias após o início do déficit hídrico, aos 65 DAS. Neste momento foi realizada a reidratação das plantas por irrigação, até o final do ciclo da cultura. Para o tratamento irrigado (I) os vasos foram periodicamente irrigados com suprimento adequado de água, até o final do ciclo da cultura.

Avaliações foram realizadas durante a imposição do déficit hídrico até a reidratação (relações hídricas); após a imposição do déficit hídrico (variáveis biométricas) e no final do ciclo da cultura (componentes da produção).

Do início da imposição do déficit hídrico até o final do período da reidratação completa das plantas (55 a 67 DAS), 
determinou-se, diariamente, o teor relativo de água das folhas (TRA), seguindo metodologia descrita por Barrs \& Weatherley (1962) e a umidade gravimétrica do solo (Ug).

Após a imposição do déficit hídrico no momento da reidratação, quando as plantas estavam com 65 DAS, foram coletadas as plantas dos 30 vasos destinados para realização das variáveis biométricas: área foliar, determinada através de amostragens, seguindo metodologia de Benincasa (2003); altura de plantas; número de perfilhos por planta e volume radicular, obtido através do método de deslocamento de líquido em proveta (Basso, 1999).

As plantas foram seccionadas separando em raiz, colmo + bainha e folha; logo em seguida, as diferentes partes da planta foram acondicionadas em sacos de papel e secadas em estufa de circulação forçada de ar a $65^{\circ} \mathrm{C}$ até atingirem massa constante, após o que foi determinada a massa utilizando-se uma balança de precisão e se obtendo, assim: fitomassa de folhas; fitomassa de bainha mais colmo; fitomassa de raízes; fitomassa da parte aérea; fitomassa total; e, razão raiz/parte aérea (relação entre a fitomassa das raízes e a fitomassa seca da parte aérea). Aos 120 DAS foram coletadas as plantas do terceiro grupo de vaso de cada tratamento, para determinação dos seguintes componentes de produção: número de perfilhos viáveis por planta, número de espiguetas por espiga; número de grãos por espiga, massa de 1000 grãos; massa de grãos por planta; e, produção.

Os dados foram submetidos à análise de variância pelo teste F e as médias das diferentes variáveis de cada tratamento foram comparadas pelo teste de Tukey a $5 \%$ de probabilidade.

\section{RESULTADOS E DISCUSSÃO}

Na Figura 1A e B são apresentados a umidade gravimétrica (Ug) do solo e o teor relativo de água (TRA) das folhas, das cultivares de trigo CD 105, CD 111 e CD 108, submetidas a déficit hídrico e reidratação no início do florescimento. Observando-se os valores médios dos tratamentos irrigados verifica-se que tanto para Ug como para TRA, estes se mantiveram constantes, com valores médios de aproximadamente $0,25 \mathrm{~g} \mathrm{~g}^{-1} \mathrm{e} 98 \%$, para a $\mathrm{Ug}$ e TRA, respectivamente.

Quanto às plantas submetidas ao déficit hídrico, verifica-se queda gradativa e constante da Ug, a partir do terceiro dia da suspensão da irrigação, atingindo valores de $0,05 \mathrm{~g} \mathrm{~g}^{-1}$, aos 10 dias após o início do déficit, momento em que se realizou a reidratação das plantas; no entanto, a queda no TRA das folhas das cultivares de trigo se iniciou aos 5, 7 e 8 dias após o início da imposição do déficit para as cultivares CD 111, CD 108 e CD 105 , respectivamente.

Foram observadas redução na Ug e TRA das plantas, em função do déficit hídrico. Contudo, iniciou-se a redução do TRA, posteriormente à redução da Ug. Deste modo, pode-se inferir sobre o papel do controle estomático no combate à desidratação foliar. $\mathrm{O}$ fechamento dos estômatos pode ser considerado um dos primeiros ajustes de desenvolvido pela planta a fim de evitar, então, a continuidade da perda de água. Da mesma forma, o potencial hídrico da planta elevado, tendo relação direta com a redução da umidade gravimétrica do solo

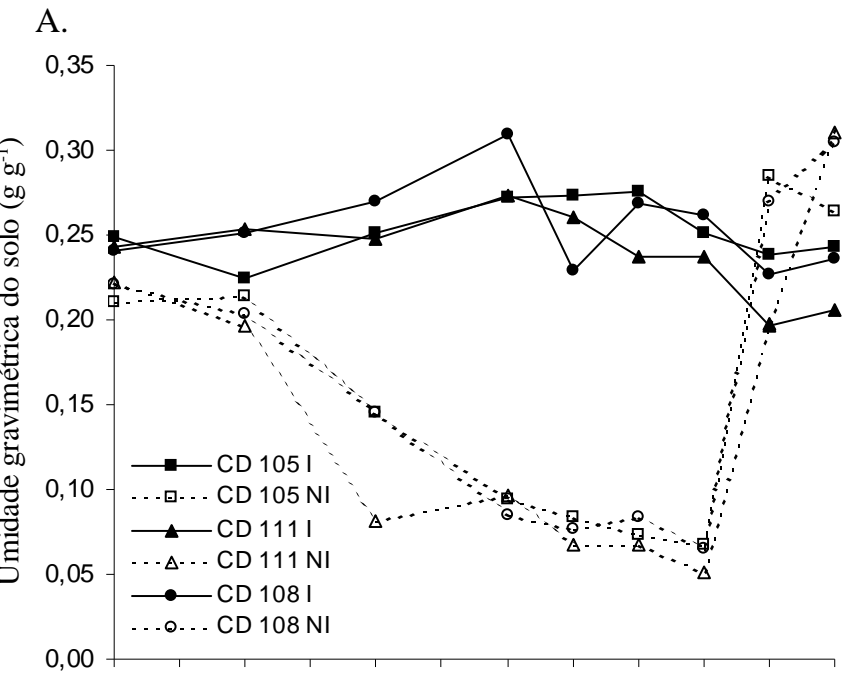

B.

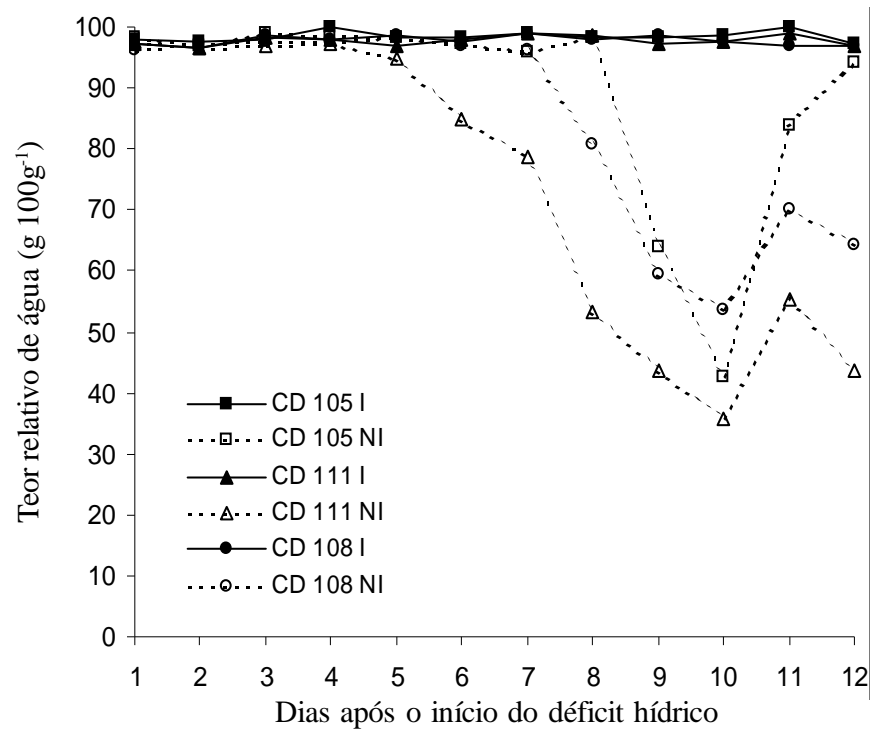

I - Irrigado durante o ciclo; $\mathrm{NI}$ - com indução de déficit hídrico no início do florescimento

Figura 1. (A) - Umidade gravimétrica do solo (Ug) e (B) - teor relativo de água das folhas (TRA), de três cultivares de trigo submetidas a déficit hídrico e reidratação a partir do início do florescimento

em resposta ao incremento da síntese de ácido abscísico (ABA) nas raízes das plantas (Taiz \& Zeiger, 2010; Nascimento et al., 2011). Ressalta-se que existe contribuição do ABA compartimentalizado na folha (Taiz \& Zeiger, 2010).

Machado \& Sassaki (1999) compararam os efeitos da deficiência hídrica sobre as trocas gasosas e o potencial de água na folha, em trigo verificando que, mesmo sob queda rápida de umidade do solo, a abertura estomática respondeu mais rapidamente à variação do conteúdo de água no solo do que à variação do potencial da água na folha.

Fumis \& Pedras (2002) relataram, estudando o efeito de déficit em cultivares de trigo, que dois dias após a reidratação a Ug do solo voltou aos valores próximos aos registrados nos tratamentos irrigados enquanto para o TRA somente a cultivar CD 105 atingiu valores semelhantes aos tratamentos irrigados. Tal fato deve ter ocorrido devido a uma adaptação das plantas às condições de déficit hídrico, o que levaria a 
sugerir maior capacidade de ajustamento osmótico das plantas dessa cultivar.

A cultivar CD 111 apresentou redução no TRA de forma mais evidente e com maior intensidade nos primeiros dias de déficit, quando comparada com as demais cultivares, o que resultou em um período maior para a recuperação da turgescência, sendo este um indicativo de sensibilidade à deficiência hídrica moderada.

Para altura de planta e área foliar verificou-se, nos diferentes tratamentos, que houve interação entre tratamentos e cultivares (Tabela 1). As três cultivares indicaram diferenças significativas nas alturas dentro de um mesmo regime e entre regimes hídricos; somente a cultivar CD 105 não apresentou diferença significativa entre os regimes para altura de plantas (Tabela 1). Constata-se, então, menor sensibilidade da cultivar CD 105 quando submetida ao déficit hídrico para altura de plantas, quando comparada com as demais cultivares.

Tabela 1. Altura de plantas e área foliar de três cultivares de trigo irrigada (I) e com indução de déficit hídrico no início do florescimento da cultura (NI)

\begin{tabular}{lccccc}
\hline \multirow{2}{*}{ Cultivar } & \multicolumn{2}{c}{ Altura de planta (cm) } & & \multicolumn{2}{c}{ Área foliar $\mathbf{( c m}^{2}$ ) } \\
\cline { 2 - 3 } \cline { 5 - 6 } CD 105 & I & NI & & I & NI \\
CD 111 & $63,60 \mathrm{aA}^{1}$ & $62,00 \mathrm{aA}$ & & $230,03 \mathrm{bA}$ & $153,88 \mathrm{aB}$ \\
CD 108 & $61,00 \mathrm{bA}$ & $58,60 \mathrm{bB}$ & & $341,72 \mathrm{aA}$ & $167,23 \mathrm{aB}$ \\
\hline Média & $55,80 \mathrm{cA}$ & $50,60 \mathrm{cB}$ & $243,36 \mathrm{bA}$ & $116,48 \mathrm{aB}$ \\
\hline QM (Cult. x Reg.) & 60,13 & 57,07 & 271,70 & 145,86 \\
DMS & \multicolumn{2}{c}{$8,93^{*}$} & & \multicolumn{2}{c}{$6.046,54^{*}$} \\
CV (\%) & \multicolumn{2}{c}{1,45} & & \multicolumn{2}{c}{46,76} \\
\hline
\end{tabular}

${ }^{1}$ Médias seguidas da mesma letra minúscula na coluna (entre cultivares) e maiúscula na linha (entre tratamentos) não diferem estatisticamente pelo teste de Tukey a 0,05 de probabilidade

Significativo pelo teste $\mathrm{F}$ a 0,05 de probabilidade

Os resultados obtidos no presente trabalho para altura das plantas, estão de acordo com a literatura constatando-se que, em geral, plantas de trigo submetidas a déficit hídrico apresentam porte reduzido quando comparadas às que se desenvolveram em condições adequadas de fornecimento de água (Fumis \& Pedras, 2002). Este fato se deve à redução da turgescência das células e de outros fatores envolvidos nos processos fisiológicos, uma vez que para existir alongamento celular são necessários níveis mínimos de turgescência (Kramer \& Boyer, 1995).

Em relação à área foliar as três cultivares apresentaram diferenças significativas quando submetidas ao déficit hídrico; contudo, a cultivar CD 111 teve maior redução na área foliar quando comparada com as demais cultivares (Tabela 1). Entre os regimes de manejo de irrigação para o tratamento irrigado, somente a cultivar CD 111 se diferenciou significativamente dos demais genótipos, desenvolvendo uma área foliar maior; já para o tratamento não irrigado não houve diferenças significativas entre as três cultivares para esta variável (Tabela 1).

Os resultados para área foliar se assemelham aos da literatura, que relata decréscimo em plantas de trigo neste parâmetro sempre que diminuiu o potencial de água no solo (Begg \& Turner, 1981; Rodrigues et al., 1998; Fumis \& Pedras, 2002), podendo-se considerar referido parâmetro como um dos principais fatores responsáveis pela menor taxa de acúmulo de fitomassa em plantas sob déficit hídrico. Segundo Coêlho \& Oliveira Júnior (1990) a redução do nível de água no solo se constitui em um dos principais fatores limitantes ao crescimento das plantas o qual depende, por sua vez, da crescente formação dos tecidos, tal como da expansão e diferenciação celular, atividades essas que são reduzidas em condições de deficiência hídrica acarretando diminuição da área foliar.

Os valores obtidos para volume radicular, fitomassa de folhas e fitomassa de colmo e bainha nos diferentes tratamentos, são encontrados na Tabela 2. Analisando-se os dados de volume radicular verifica-se que não houve diferenças significativas entre cultivares; no entanto, houve uma redução significativa do volume radicular no regime de déficit quando comparado com o regime sem déficit. De acordo com Fumis \& Pedras (2002), o déficit hídrico favorece o desenvolvimento do sistema radicular durante o estádio vegetativo, comparativamente à parte aérea da maioria das culturas. Este fenômeno atua em todo o crescimento da planta reduzindo seu potencial de crescimento na parte aéreaporém estimulando o crescimento das raízes, na tentativa de alcançar água em maiores profundidades do solo (Soares \& Nascimento, 1998).

Tabela 2. Volume radicular, massa seca (MS) de folhas e massa seca de colmo + bainha, de três cultivares de trigo, irrigadas (I) e com indução de déficit hídrico no início do florescimento da cultura (NI)

\begin{tabular}{lccc}
\hline & $\begin{array}{c}\text { Volume } \\
\text { radicular }\left(\mathbf{c m}^{3}\right)\end{array}$ & $\begin{array}{c}\text { MS de } \\
\text { folhas }(\mathbf{g})\end{array}$ & $\begin{array}{c}\text { MS colmo + bainha } \\
\mathbf{( g )}\end{array}$ \\
Cultivar & & & \\
CD 105 & $52,20 \mathrm{a}^{1}$ & $7,34 \mathrm{a}$ & $9,61 \mathrm{a}$ \\
CD 111 & $49,60 \mathrm{a}$ & $8,41 \mathrm{a}$ & $8,65 \mathrm{a}$ \\
CD 108 & $44,90 \mathrm{a}$ & $5,98 \mathrm{~b}$ & $7,16 \mathrm{~b}$ \\
DMS & 15,24 & 1,14 & 1,16 \\
\hline Regime & & & \\
I & $59,33 \mathrm{a}$ & $8,94 \mathrm{a}$ & $9,72 \mathrm{a}$ \\
NI & $38,46 \mathrm{~b}$ & $5,55 \mathrm{~b}$ & $7,22 \mathrm{~b}$ \\
Média & 48,90 & 7,24 & 8,47 \\
QM (Cult. x Reg.) & $429,43^{\text {ns }}$ & $3,40^{\star}$ & $0,19^{\text {ns }}$ \\
DMS & 10,29 & 0,77 & 0,79 \\
CV (\%) & 27,92 & 14,07 & 12,31 \\
\hline
\end{tabular}

${ }^{1}$ Médias seguidas da mesma letra não diferem estatisticamente pelo teste de Tukey a 0,05 de probabilidade

"Significativo pelo teste $\mathrm{F}$ a 0,05 de probabilidade

Em relação à razão raiz/parte aérea, não se constatou diferença significativa neste trabalho. No entanto, Lawlor \& Uprety (1993) afirmaram haver aumento da razão raiz/parte aérea em muitas culturas sob seca, o que é atribuído à grande alocação de carbono às raízes. E em adição à redução na taxa de uso de água pela redução da área foliar, existe evidência de aumento no acesso da água do solo, através de um aumento na razão raiz/parte aérea em plantas de trigo (Begg \& Turner, 1981). Tem-se observado também, em outros trabalhos, que tal fato depende da intensidade e duração do déficit hídrico, tal como o estádio em que ele ocorre.

Para massa seca de folha e massa seca de colmo e bainha, a cultivar CD 108 obteve resultados inferiores aos das demais. Também ocorreu redução significativa da massa seca de folhas, colmo e bainha, no regime com imposição de déficit hídrico em relação ao regime irrigado normalmente. Esses resultados estão 
concordantes com Poustini et al. (2007), que revelaram diminuição de matéria seca de folhas e colmo em plantas de trigo, com a imposição de déficit hídrico, ao afirmarem que os resultados coincidem com o verificado para área foliar indicando que, devido à redução hídrica, a redução da matéria seca de folhas, afeta a área foliar.

$\mathrm{Na}$ Tabela 3 se encontram os valores da massa seca de estrutura reprodutiva, massa seca de parte aérea e massa seca total. Verificou-se diferença significativa entre regimes hídricos e entre cultivares; no entanto, não houve interação entre regime e cultivares para essas variáveis. De maneira geral, o déficit hídrico afetou negativamente o desenvolvimento das plantas reduzindo essas variáveis biométricas, quando comparando com as plantas que foram mantidas em hidratação satisfatória durante todo o ciclo, exceto para a variável massa seca de estrutura reprodutiva, que foi estatisticamente semelhante nos dois regimes hídricos. A cultivar com menor massa seca de estrutura reprodutiva foi a CD 111.

Tabela 3. Fitomassa seca de estrutura reprodutiva (MSEP), fitomassa seca de parte aérea (MSPA) e fitomassa seca total (MST) de três cultivares de trigo irrigadas (I) e com indução de déficit hídrico no início do florescimento da cultura (NI)

\begin{tabular}{lccc}
\hline & MSEP (g) & MSPA (g) & MST (g) \\
Cultivar & & & \\
CD 105 & $4,77 \mathrm{a}^{1}$ & $21,72 \mathrm{a}$ & $34,11 \mathrm{a}$ \\
CD 111 & $3,39 \mathrm{~b}$ & $20,45 \mathrm{a}$ & $32,26 \mathrm{a}$ \\
CD 108 & $4,54 \mathrm{a}$ & $17,68 \mathrm{~b}$ & $29,85 \mathrm{a}$ \\
d.m.S. & 0,94 & 2,49 & 7,95 \\
\hline Regime & & & \\
I & $4,48 \mathrm{a}$ & $23,14 \mathrm{a}$ & $37,35 \mathrm{a}$ \\
NI & $3,99 \mathrm{a}$ & $16,76 \mathrm{~b}$ & $26,80 \mathrm{~b}$ \\
Média & 4,23 & 19,95 & 32,07 \\
QM (Cult. x Reg.) & $0,40^{\text {ns }}$ & $8,41^{\text {ns }}$ & $50,77^{\text {ns }}$ \\
DMS & 0,63 & 1,68 & 5,37 \\
CV (\%) & 19,79 & 11,18 & 22,21 \\
\hline Médias seguidas da mesma
\end{tabular}

${ }^{1}$ Médias seguidas da mesma letra não diferem estatisticamente pelo teste de Tukey a 0,05 de probabilidade. Significativo pelo teste $\mathrm{F}$ a 0,05 de probabilidade

Frequentemente, plantas sob condições inadequadas de fornecimento de água apresentam menor produção de massa seca quando comparadas com aquelas mantidas a elevados potenciais da água no solo. Com o déficit hídrico há fechamento dos estômatos e consequente diminuição da fotossíntese. Como a redução da fotossíntese é mais rápida que a redução da taxa respiratória, há uma consequente diminuição na produção de massa seca, como descrito por Endres et al. (2010).

De maneira geral e segundo Rodrigues \& Urchei (1994) para que o desenvolvimento das espécies vegetais ocorra de modo satisfatório, ou seja, para que a acumulação de massa seca decorrente da síntese de carboidratos se processe de maneira eficiente, os fatores água e luz são essenciais, evidenciando a importância da irrigação como mecanismo de suprir prováveis deficiências hídricas, durante o ciclo fenológico das culturas.

Na Tabela 4 são apresentados os dados referentes ao número de perfilhos por planta, número de grãos por planta e número de espigas por perfilhos viáveis, em que houve diferença significativa entre regime e entre cultivares. Constatou-se redução significativa do número de perfilhos por planta no regime de déficit hídrico. Entre as variedades ocorreu diferença significativa do número de perfilhos e a cultivar CD 105. Embora a fase de perfilhamento já tivesse ocorrido muito antes do início da imposição do déficit hídrico, acredita-se que a redução do número de perfilhos tenha ocorrido pela necessidade da planta em diminuir a área foliar, aumentando a senescência das folhas e, consequentemente, a morte dos perfilhos.

Tabela 4. Número de perfilhos por planta (NPP), número de grãos por planta (NGP) e número de espigas por perfilhos viáveis (NESPPER) de três cultivares de trigo irrigado (I) e com indução de déficit hídrico no início do florescimento da cultura (NI)

\begin{tabular}{lccc}
\hline & NPP & NGP & NESPPER \\
Cultivar & & & \\
CD 105 & $8,55 \mathrm{c}^{1}$ & $461,80 \mathrm{a}$ & $21,80 \mathrm{c}$ \\
CD 111 & $10,65 \mathrm{~b}$ & $544,50 \mathrm{a}$ & $28,90 \mathrm{~b}$ \\
CD 108 & $12,27 \mathrm{a}$ & $503,20 \mathrm{a}$ & $37,10 \mathrm{a}$ \\
DMS & 6,34 & 183,66 & 6,09 \\
\hline Regime & & & \\
I & $11,38 \mathrm{a}$ & $629,80 \mathrm{a}$ & $27,87 \mathrm{a}$ \\
NI & $9,60 \mathrm{~b}$ & $376,53 \mathrm{~b}$ & $30,67 \mathrm{a}$ \\
Média & 10,49 & 503,17 & 29,27 \\
QM (Cult. x Reg.) & $96,63^{\text {ns }}$ & $9.862,43^{\text {ns }}$ & $81,70^{\text {ns }}$ \\
DMS & 4,28 & 124,04 & 4,11 \\
CV (\%) & 13,53 & 32,70 & 18,63 \\
\hline
\end{tabular}

${ }^{1}$ Médias seguidas da mesma letra não diferem estatisticamente pelo teste de Tukey a 0,05 de probabilidade

Significativo pelo teste $\mathrm{F}$ a 0,05 de probabilidade

Com relação ao número de espigas por perfilhos viáveis não houve diferença significativa entre regimes, embora o déficit tenha reduzido significativamente o número de grãos por planta. Os resultados obtidos com relação ao número de espigas diferiram dos citados pela literatura, os quais têm reportado diminuição do número de espigas com a ocorrência de déficits hídricos. Akhkha et al. (2011) verificaram, estudando respostas de plantas de trigo quanto à imposição do déficit hídrico em diferentes estádios do desenvolvimento de trigo (perfilhamento, emborrachamento, enchimento de grãos e maturação fisiológica) redução do número de espigas quando submetidas a déficits hídricos. É provável que a época da imposição do déficit hídrico, início do florescimento, pode ter influenciado nos resultados obtidos para este ensaio de vez que não limitou o número de espigas mas sim o número de grãos nas plantas.

Para o número de espiguetas por espiga, número de grãos por espiga e massa de grãos em cinco espigas, houve interação entre cultivares e tratamentos (Tabela 5). Pode-se observar, no regime sem imposição do déficit hídrico, diferença significativa entre as três cultivares em relação ao número de espiguetas por espigas, com o menor valor médio para a cv. CD 108. No entanto, quando presente o déficit hídrico, nota-se que a cultivar CD 105 respondeu melhor quando comparada com as demais cultivares, em relação ao número de espiguetas por espigas. Por outro lado, para a mesma variável somente a cultivar CD 111 foi a única cultivar que apresentou redução significativa quando presente a restrição hídrica.

Os resultados obtidos neste trabalho diferem dos divulgados por Frizzone \& Olitta (1990), ao analisarem o efeito 
Tabela 5. Número de espiguetas por espigas (NEPESP), número de grãos por espiga (NGESP) e massa de grãos em cinco espigas (MGESP) de três cultivares de trigo irrigadas (I) e com indução de déficit hídrico no início do florescimento da cultura (NI)

\begin{tabular}{|c|c|c|c|c|c|c|}
\hline \multirow{2}{*}{ Cultivar } & \multicolumn{2}{|c|}{ NEPESP } & \multicolumn{2}{|c|}{ NGESP } & \multicolumn{2}{|c|}{ MGESP (g) } \\
\hline & $I$ & NI & $I$ & NI & $I$ & NI \\
\hline $\begin{array}{l}\text { CD } 105 \\
\text { CD } 111 \\
\text { CD } 108\end{array}$ & $\begin{array}{c}19,40 \mathrm{aA}^{1} \\
17,12 \mathrm{bA} \\
14,68 \mathrm{Ca}\end{array}$ & $\begin{array}{l}17,88 \mathrm{aA} \\
14,92 \mathrm{bB} \\
15,60 \mathrm{bA}\end{array}$ & $\begin{array}{l}43,46 \mathrm{aA} \\
35,16 \mathrm{abA} \\
27,56 \mathrm{bA}\end{array}$ & $\begin{array}{l}18,84 \mathrm{aB} \\
15,18 \mathrm{aB} \\
19,96 \mathrm{aA}\end{array}$ & $\begin{array}{l}8,40 \mathrm{aA} \\
6,40 \mathrm{abA} \\
4,41 \mathrm{bA}\end{array}$ & $\begin{array}{l}3,25 a B \\
2,39 a B \\
2,71 a A\end{array}$ \\
\hline Média & 17,07 & 16,13 & 35,39 & 17,99 & 6,40 & 2,78 \\
\hline $\begin{array}{l}\text { QM (Cult. x Reg.) } \\
\text { DMS } \\
\text { CV (\%) }\end{array}$ & & & & & & \\
\hline
\end{tabular}

${ }^{1}$ Médias seguidas da mesma letra minúscula na coluna (entre cultivares) e maiúscula na linha (entre tratamentos) não diferem estatisticamente pelo testede Tukey a 0,05 de probabilidade "Significativo pelo teste $\mathrm{F}$ a 0,05 de probabilidade

de supressão de água em diferentes fases do crescimento na produção do trigo, não constatando diferença significativa do número de espiguetas por espiga entre os tratamentos. $\mathrm{Na}$ avaliação do número de grãos por espiga no regime sem imposição de déficit hídrico, a cultivar CD 111 não sinalizou diferença significativa em relação à cultivar $C D 105$ nem para com a CD 108. No regime com imposição de déficit hídrico não houve diferenças significativas entre as cultivares avaliadas. Entre os regimes, ocorreu redução significativa no número de grãos por espiga nas cultivares CD 105 e CD 111, mas não foi observado o mesmo na cultivar CD 108. Resultados similares em função dos tratamentos, foram observados em massa de grãos.

Conforme constatado por Rodrigues et al. (1998), a deficiência hídrica afetou negativamente o rendimento de grãos de trigo, sobretudo pela diminuição do número de grãos por área, correlacionando-se mais com o número de grãos por espiga ao invés do número de espigas. Referidos resultados indicam a maior influência da deficiência hídrica no número de grãos por espiga e não na fitomassa de grãos, caracterizando assim a fase de pré-antese como a mais sensível a deficiência hídrica.

Os resultados referentes à massa de 1000 grãos (MMG) e produção de grãos estão representados da Tabela 6. Com referência à MMG, somente a cultivar CD 105 apresentou

Tabela 6. Massa de 1000 grãos (MMG) e produção por planta (PROD) de três cultivares de trigo irrigadas (I) e com indução de déficit hídrico no início do florescimento da cultura $(\mathrm{NI})$

\begin{tabular}{lcc}
\hline & MMG (g) & PROD (g plantas $^{-1}$ ) \\
Cultivar & & \\
CD 105 & $35,65 \mathrm{a}^{1}$ & $4,23 \mathrm{a}$ \\
CD 111 & $25,64 \mathrm{~b}$ & $3,67 \mathrm{a}$ \\
CD 108 & $28,03 \mathrm{~b}$ & $3,65 \mathrm{a}$ \\
DMS & 4,71 & 1,49 \\
\hline Regime & & \\
I & $35,26 \mathrm{a}$ & $5,5 \mathrm{a}$ \\
NI & $24,29 \mathrm{~b}$ & $2,2 \mathrm{~b}$ \\
Média & 29,77 & 3,85 \\
QM (Cult. x Reg.) & $48,23^{\text {ns }}$ & $5,48^{\text {ns }}$ \\
d.m.s. & 3,18 & 1,01 \\
CV (\%) & 14,18 & 34,65 \\
\hline
\end{tabular}

${ }^{1}$ Médias seguidas da mesma letra não diferem estatisticamente pelo teste de Tukey a 0,05 de probabilidade. ${ }^{\text {ns }}$ Significativo pelo teste $\mathrm{F}$ a 0,05 de probabilidade diferença significativa em relação às outras duas cultivares. Também ocorreu redução significativa na massa de 1000 grãos quando as plantas foram submetidas ao regime de déficit hídrico.

Os resultados corroboram com os relatados por Moreira et al. (1999) que, estudando irrigação de trigo em solo sob vegetação de cerrado, verificaram efeito positivo das maiores lâminas de água sobre o peso de 1000 grãos. No entanto, resultados diferentes foram encontrados por outros autores, ao avaliar o efeito da restrição hídrica (Fumis \& Pedras, 2002) ou em solos encharcados (Calheiros et al., 2000) em função de diferente cultivares de trigo, não obtendo diferença significativa na massa de 1000 grãos.

Apesar da cultivar CD 111 ter sido mais afetada nas variáveis (TRA, área foliar, fitomassa de estrutura reprodutiva e número de espiguetas por espiga), não houve diminuição significativa na produção de grãos por planta, entre as cultivares avaliadas no regime com déficit hídrico, embora tenha havido redução significativa na produtividade, quando as plantas foram submetidas ao regime de déficit hídrico no início do florescimento, cujos resultados estão de acordo com Rodrigues et al. (1998) trabalhando com plantas de trigo submetidas ao déficit hídrico.

\section{CONCLusões}

1. As plantas que sofreram déficit hídrico no início do período de florescimento tiveram menor produção de fitomassa e produção de grãos;

2. A Cultivar CD 111 se mostra mais eficiente na manutenção do potencial produtivo em condições de déficit hídrico, mediante a rápida recuperação do teor relativo de água nas folhas.

\section{LITERATURA CITADA}

Akhkha, A.; Boutraa, T.; Alhejely, A. The rates of photosynthesis, chlorophyll content, dark respiration, proline and abscicic acid (ABA) in wheat (Triticum durum) under water deficit conditions. International Journal of Agriculture and Biology, v.13, p.215-221, 2011. 
Barrs, H. D.; Weatherley, P. E. A re-examination of the relative turgidity technique for estimating water deficits in leaves. Australian Journal of Biological Sciences. v. 15, p.413-428, 1962.

Basso, S. M. S. Caracterização morfológica e fixação biológica de nitrogênio de espécies de Adesmia DC. e Lotus L. Porto Alegre: UFRGS, 1999. 268p. Tese Doutorado

Begg, J. E.; Turner, N. C. Plant-water relations and adaptation to stress. Plant and Soil, Netherlands: ICARDA, 1981. Cap.5, p.97-131.

Benincasa, M. M. P. Análise de crescimento de plantas (noções básicas). 2.ed. Jaboticabal: FUNEP, 2003. 41p.

Boschini, A. P. M.; Silva, C. L. da; Oliveira, C. A. da; Oliveira Júnior, M. P. de; Miranda, M. Z. de; Fagioli, M. Aspectos quantitativos e qualitativos do grão de trigo influenciados por nitrogênio e lâminas de água. Revista Brasileira de Engenharia Agrícola e Ambiental, v.15, p.450-457, 2011.

Brunetta, D.; Bassoi, M. C.; Dotto, S. R.; Scheeren, P. L.; Miranda, M. Z.; Tavares, L. C. V.; Miranda, L. C. Características e desempenho agronômico da cultivar de trigo BRS 229 no Paraná. Pesquisa Agropecuária Brasileira, v.41, p.889-892, 2006.

Calheiros, R. de O.; Cruciani, D. E.; Arruda, F. B.; Voltan, R. B. Q.; Sakai, E.; Pires, R. C. de M. Efeito do manejo do lençol freático na adaptação fisiomorfológica de duas espécies de trigo ao encharcamento. Revista Brasileira de Engenharia Agrícola e Ambiental, v.4, p.194-202, 2000.

Carvalho, F. E. L.; Lobol, A. K. M.; Bonifácio, A.; Martins, M. O.; Lima Neto, M. C.; Silveira, J. A. G. Aclimatação ao estresse salino em plantas de arroz induzida pelo pré-tratamento com $\mathrm{H}_{2} \mathrm{O}_{2}$. Revista Brasileira de Engenharia Agrícola e Ambiental, v.15, p.416-423, 2011.

Coêlho, K. J. F.; Oliveira Júnior, J. O. L. Efeito da deficiência hídrica no solo sobre a eficiência no uso de água e a produção de matéria seca de duas cultivares de milho (Zea mays). Agropecuária Técnica, v.11, p.24-40, 1990.

COODETEC - Cooperativa Central de Pesquisa Agrícola. http://www.coodetec.com.br. 26 Jan. 2012.

Cunha, G. R. da; Haas, J. C.; Muluf, J. R. T.; Caramori, P. H.; Assad, E. D.; Braga, H. J.; Zullo Júnior, J.; Lazzarotto, C.; Gonçalves, S.; Wrege, M.; Brunetta, D.; Dotto, S. R.; Pinto, H. S; Brunini, O.; Thomé, V. M. R.; Zampieri, S. L.; Pasinato, A.; Pimentel, M. B. M.; Pandolfo, C. Zoneamento agrícola e época de semeadura para trigo no Brasil. Revista Brasileira de Agrometeorologia, v.9, p.400-414, 2001.

Endres, L.; Souza, J. L. de; Teodoro, I.; Marroquim, P. M. G.; Santos, C. M dos; Britos, J. E. D. de. Gas exchange alteration caused by water deficit during the bean reproductive stage. Revista Brasileira de Engenharia Agrícola e Ambiental, v.14, p.11-16, 2010.

Finkelstein, R.; Lynch, T.; Reeves, W.; Petitfils, M.; Mostachetti, M. Accumulation of the transcription factor ABAinsensitive (ABI) 4 is tightly regulated post-transcriptionally. Journal of Experimental Botany, v.19, p.1-9, 2011.

Frizzone, J. A.; Olitta, A. F. L. Efeitos da supressão de água em diferentes fases do crescimento na produção do trigo. Engenharia Rural, v.1, p.23-14, 1990.
Fumis, T. de F.; Pedras, J. F. Variação nos níveis de prolina, diamina e poliaminas em cultivares de trigo submetidas a déficits hídricos. Pesquisa Agropecuaria Brasileira, v.37, p.449-453, 2002.

Gutkoski, L. C.; Klein, B.; Pagnussatt, F. A.; Pedó, I. Características tecnológicas de genótipos de trigo (Triticum aestivum L.) cultivados no cerrado. Ciência e Agrotecnologia, v.31, p.786-792, 2007.

Kramer, P. J.; Boyer, J. S. Water relations of plants and soils. San Diego: Academic Press, 1995. 495p.

Lawlor, D. W.; Uprety, D. C. Effects of water stress on photosynthesis of crops and the biochemical mechanism. In: Abrol YP, Mohanty P, Govinjee, eds. Photosynthesis: photoreactions to plant productivity. New Dehli: Oxford and IBH Publishing Co. PVT. Ltd v.1, 1993. p.419-449.

Machado, E. C.; Sassaki, R. M. Trocas gasosas e condutância estomática em duas espécies de trigo em diferentes teores de água no solo. Pesquisa Agropecuária Brasileira, v.34, p.1571-1579, 1999.

Moreira, J. A. A.; Stone, L. F.; Trindade, M. da G.; Cánovas, A. D. Manejo da irrigação para o trigo no sistema plantio direto. Santo Antônio de Goiás: EMBRAPA, 2004. 8p. Circular Técnica, 91

Moreira, M. A.; Angulo Filho, R.; Rudorff, B. F. T. Eficiência do uso da radiação e índice de colheita em trigo submetido a estresse hídrico em diferentes estádios de desenvolvimento. Scientia Agricola, v.56, p.597-603, 1999.

Nascimento, S. P. do; Bastos, E. A.; Araujo, E. C. E.; Freire Filho, F. R.; Silva, E. M. da. Tolerância ao déficit hídrico em genótipos de feijão-caupi. Revista Brasileira de Engenharia Agrícola e Ambiental, v.15, p.853-860, 2011.

Poustini, K.; Siosemardeh, A.; Ranjbar, M. Proline accumulation as a response to salt stressing 30 wheat (Triticum aestivum L.) cultivars differing in salt tolerance. Genet Resources and Crop Evolution, v.54, p.925-934, 2007.

Rodrigues, J. D.; Urchei, M. A. Efeitos de potenciais de água no solo, em diferentes estádios fenológicos da cultura da cevada (Hordeum vulgare L.). Scientia Agrícola, v.51, p.533540, 1994.

Rodrigues, O.; Lhamby, J. C. B.; Didonet, A. D.; Marchese, J. A.; Scipioni, C. Efeito da deficiência hídrica na produção de trigo. Pesquisa Agropecuária Brasileira, v.33. p.839-846, 1998.

Soares, J. M.; Nascimento, T. Distribuição do sistema radicular da videira em vertissolo sob irrigação localizada. Revista Brasileira de Engenharia Agrícola e Ambiental, v.2, p.142147, 1998.

Sousa, M. A. de; Lima, M. D. B. Influência da supressão da irrigação em estádios de desenvolvimento do feijoeiro cv. Carioca comum. Bioscience Journal, v.26, p.550-557, 2010.

Taiz, L.; Zeiger, E. Pant Physiology, 5.ed. Sunderland: Sinauer Associates Inc. Publishers, 2010. 782p.

Tavares, L. C. V.; Bassoi, M. C.; Miranda, L. C.; Prete, C. E. C. Transferência de tecnologia para cultivares de trigo no estado do Paraná. Revista Brasileira de Sementes, v.33, p.2127, 2011. 